\title{
Tissue Gystathionine in Mice Treated with Cysteine and Homoserine
}

\author{
Paul W. K. Wong ${ }^{[45]}$ and Raoul Fresco \\ Department of Pediatrics and Department of Experimental Pathology, Chicago Medical School/University of Health Sciences \\ and the Mount Sinai Hospital Medical Center, Chicago, Illinois, USA
}

\section{Extract}

Mouse brain was demonstrated to concentrate DL-homoserine and L-cysteine from plasma. Simultaneous injection of $7.5 \mu$ moles DL-homoserine and L-cysteine intraperitoneally to mice resulted in a marked increase of brain cystathionine at the end of $5 \mathrm{hr}$. The concentration of cystathionine in the experimental group $(0.143 \pm 0.022$ $\mu$ mole $/ \mathrm{g})$ was more than 6 times that of the control group $(0.023 \pm 0.011 \mu \mathrm{mole} / \mathrm{g})$. By using unlabeled DL-homoserine and DL-cysteine- ${ }^{35} \mathrm{~S}$ for injection, cystathionine in brain was found to be labeled, with a specific activity $(67,800 \mathrm{dpm} / \mu \mathrm{mole})$ approximately half that in the radioactive cysteine $(115,000 \mathrm{dpm} / \mu$ mole $)$. These observations suggest that approximately half the cystathionine in brain has been derived from cysteine and, presumably, homoserine. The remaining half is presumed to have been derived from methionine.

Chronic feeding of diets containing $5 \%, 2 \%$, and $1 \%$ DL-homoserine and L-cysteine, $5 \%$ and $2 \%$ DL-homoserine, and $5 \%, 2 \%$, and $1 \%$ L-cysteine to weanling mice resulted in a significant increase in cystathionine in brain compared with controls $(0.148 \pm 0.016,0.049 \pm 0.002,0.044 \pm 0.002,0.040 \pm 0.001,0.043 \pm 0.003$, $0.069 \pm 0.003,0.036 \pm 0.002,0.034 \pm 0.002$, and $0.027 \pm 0.003 \mu \mathrm{mole} / \mathrm{g}, \mathrm{re}-$ spectively).

After 34 weeks of dietary experiments, the animals fed with diets containing $5 \%$, $2 \%$, and $1 \%$ of both DL-homoserine and L-cysteine, $5 \%$ DL-homoserine, and $5 \%$ and $2 \%$ L-cysteine had significantly lower body weight than that of the controls $(22.02 \pm$ $0.290,26.00 \pm 0.460,26.40 \pm 0.462,25.50 \pm 0.504,23.10 \pm 0.388,25.82 \pm 0.512$, and $28.53 \pm 0.786 \mathrm{~g}$, respectively). The lower weight gained in the experimental animals was correlated with less food intake.

Autopsy on all the experimental animals and light microscopy of their brains, lungs, hearts, livers, spleens, suprarenals, kidneys, and intestines showed no pathology. However, electron microscopy of the livers of animals fed with diets containing $5 \%$ cysteine showed subcellular changes compatible with poor nutrition, possibly related to inadequate food intake.

Animals on all the experimental diets remained fertile; they conceived and produced normal litters.

\section{Speculation}

The observations reported in this paper demonstrated that cystathionine in brain was increased when mice were given cysteine and homoserine either by intraperi- 
toneal loading or by chronic feeding. It is very probable that tissue cystathionine (particularly that of the brain) may be increased in patients with homocystinuria when adequate amounts of cysteine (or cystine) and homoserine are supplied in the diet. Excessive cysteine may produce unpalatability of the diet. However, this may be corrected by reducing the quantity of cysteine added, flavoring the diet, or by replacing the cysteine with cystine or calcium cystinate. Supplementation of cysteine (or cystine) and homoserine may be the only way to correct cystathionine deficiency in patients with pyridoxine-resistant homocystinuria.

Our observations provide the biochemical basis for investigating the possible therapeutic value of supplementing the diet of homocystinuric patients with cysteine (or cystine) and homoserine.

\section{Introduction}

Classical homocystinuria was discovered by Field et al. [12], in Northern Ireland and by Gerritsen et al. [14] in the United States. Mudd and his associates [23] demonstrated that the biochemical defect in these patients was due to the deficiency of cystathionine synthase (EC. 4.2.1.21) (Fig. 1). As a result of this metabolic block, little or no cystathionine is synthesized from homocysteine and serine in the liver and the brain; the endogenous formation of cysteine is impaired. Tallan et al. [29] found higher concentrations of cystathionine in human and monkey brains than in those of other animals. However, little or no cystathionine was found in the brains of untreated homocystinuric patients at necropsy [4]. These observations gave rise to the speculation that cystathionine may be important in the function of normal human brains and that its deficiency may be a causal factor in the mental defect in the patients with classical homocystinuria.

Matsuo and Greenberg [21] crystalized the enzyme cystathionase (EC. 4.2.1.15) from rat liver that cleaved cystathionine into cysteine and, presumably, homoserine as the initial products. However, homoserine was not released into the incubation medium but was considered to be enzyme-bound. Removal of water from homoserine produced vinylglycine, which was finally hydrolyzed by the same enzyme protein into ammonia and $\alpha$-oxobutyrate. This purified enzyme was able to catalyze the formation of cystathionine from homoserine and cysteine [9, 21]. Cystathionase activity (cleavage of cystathionine) was demonstrated in the brain of a homocystinuric patient by Laster et al. [19]. These observations suggest that normal subjects and homocystinuric patients may also be able to synthesize cystathionine from homoserine and cysteine. In 1968, Wong et al. [32] demonstrated that liver homogenates from normal humans and from patients with homocys- tinuria were able to synthesize cystathionine from homoserine and labeled cysteine. Oral loading of homoserine and cystine (or cysteine) in two patients with homocystinuria resulted in increased excretion of cystathionine in their urine. However, it has not been demonstrated whether the cystathioninuria following loading with homoserine and cysteine was associated with increased cystathionine in the tissues, particularly in the brain. The long term effect of homoserine and cysteine administration is unknown.

This paper reports the results of studies on tissue concentration of cystathionine in mice treated with homoserine and cysteine, and observations on the effect of prolonged administration of these amino acids in mice.

Materials and Methods

\section{Chemicals}

After treatment of the L-cysteine [33] with $N$-ethylmaleimide (NEM) [10] or with iodoacetate [5], ion-ex-

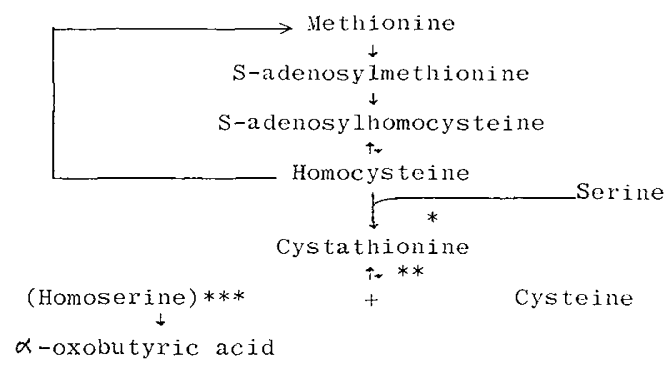

Fig. 1. Pathways of methionine metabolism. *: Cystathionine synthase (EC. 4.2.1.21). **: Cystathionase (EC. 4.2.1.15). ***: Free homoserine is not found as a product of the reaction, but is presumed to be enzyme-bound. 
change chromatography showed that the purity of cysteine was more than $99 \%$. Less than $1 \%$ was in the form of cystine. No ninhydrin peak was found in the region of the chromatograms where cystathionine was expected in the untreated, NEM-treated or iodoacetate-treated cysteine.

Ion-exchange chromatography of the DL-homoserine [34] showed no additional ninhydrin-positive peaks, including the region of the chromatogram where cystathionine was expected.

DL-Cystathionine (a mixture of 4 isomers of cystathionine and allocystathionine) [33] was eluted on ion-exchange chromatography as a single peak in front of methionine, and was used as standard for the calculation of tissue cystathionine.

The purity of the DL-cysteine-355 [35] was the same as previously stated [32], and it did not contain any ninhydrin-positive peaks nor radioactive peaks in the region of cystathionine on ion-exchange chromatography.

\section{Ion-exchange Chromatography}

Ion-exchange chromatography of amino acids was carried out by a modification of the method of Spackman et al. [27], using a Technicon amino acid analyzer [36]. Thiodiglycol was used as the antioxidant; norleucine and $\alpha$-amino-butyric acid were used as internal standards. The identity of the individual amino acid was verified by adding an authentic marker to the samples. Duplicate runs gave reproducibility within $5 \%$ in quantities above $0.01 \mu$ mole.

Collection of fractions was carried out by a Jeolco automatic amino acid analyzer [37] and Fracto-Mette (model 200). Identity of the individual fraction in relation to the ninhydrin peaks was confirmed by using an event marker.

\section{Determination of Radioactivity}

Radioactive fractions of the effluent from the Jeolco amino acid analyzer were counted by using an automatic liquid scintillation counter [38]. The fractions $(0.75 \mathrm{ml})$ were added to $15 \mathrm{ml}$ Bray's solution [3] without desalting. The counting efficiency of this method was $79 \%$. Correction for radioactive decay was carried out. The radioactivity of the DL-cysteine ${ }^{35} \mathrm{~S}$ was determined by diluting a known amount with buffer and counting in the same manner as the fractions. The specific activity of the radioactive amino acids was calculated in the same way as reported previously [32].

Localization of radioactivity on paper chromatograms was carried out as previously described [32].

\section{Animals}

For the experiments of intraperitoneal loading of cysteine or homoserine, Swiss white mice were used [39]. Weanling mice [40] were used for the dietary and breeding experiments.

\section{Diets}

The amino acid content of the control diet [41] was determined by both acid ( $6 \mathrm{~N} \mathrm{HCl}$ ) and alkaline $\left(\mathrm{Ba}(\mathrm{OH})_{2}\right)$ [20] hydrolysis for $0,24,48,55,72$, and 120 hr, according to the scheme suggested by Tristram [30]. The samples to be hydrolyzed were sealed in vacuum hydrolysis tubes with nitrogen and heated with a precision oven at $110^{\circ}$ (temperature variation was less than $\pm 1^{\circ}$ ). Correction for losses caused by hydrolysis and degradation of amino acids was made by extrapolating to zero time.

Experimental diets [42] were made by adding varying amounts of cysteine, homoserine, or both, to the control diet.

\section{Light Microscopy}

At autopsy, representative blocks of tissue from the various organs were fixed immediately in $10 \%$ buffered formalin. They were embedded and stained by the usual histologic techniques for light microscopy. Serial sections of the brain were stained with KlüverBarrera stain.

\section{Electron Microscopy}

Representative blocks of tissue from the various organs were fixed in glutaraldehyde and postfixed in osmium tetroxide. After dehydration, the tissues were embedded in Epon 812; ultrathin sections were cut for electron microscopy.

\section{Experiments and Results}

\section{Intraperitoneal Loading Experiments}

Young adult Swiss white mice were used for these experiments. $7.5 \mu$ moles DL-homoserine/g body weight in normal saline were injected intraperitoneally. The animals were anesthetized with ether $0,0.5,1,2,3,4$, and $5 \mathrm{hr}$ after injection, and the abdomen, thorax, and skull were opened.

Blood was obtained by cardiac puncture, using ethylenediaminetetraacetic acid (EDTA) as the anticoagulant. Five-tenths milliliter blood was immediately mixed with $0.5 \mathrm{ml} \mathrm{NEM} \mathrm{(containing} 100 \mu$ moles $/ \mathrm{ml}$ NEM in $0.1 \mathrm{M}$ phosphate buffer, $\mathrm{pH} 7.4$ ); norleucine 


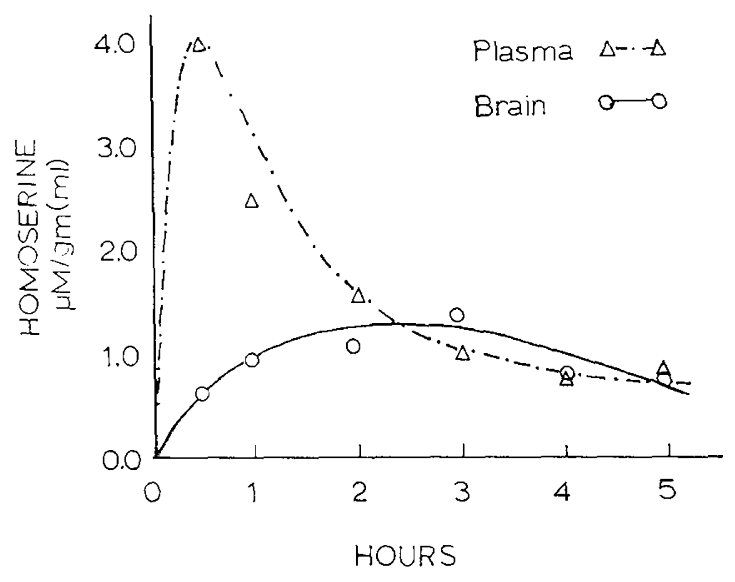

Fig. 2. Homoserine in plasma and brain of mice after intraperitoneal injection of homoserine. No homoserine is detected in the plasma or brain at 0 time.

was added as internal standard and the mixture was centrifuged. The supernatant fluid was deproteinized with $20 \%$ sulfosalycilic acid $(3: 1, \mathrm{v} / \mathrm{v})$ within $10 \mathrm{~min}$. Preliminary experiments demonstrated that the reaction of NEM with cysteine was complete within 1 min and that no significant loss of cystathionine or homoserine occurred within $15 \mathrm{~min}$. After precipitation and centrifugation, the clear supernatant fluid was frozen at $-35^{\circ}$ until it was used for ion-exchange chromatography.

Liver and brain tissue (300-400 mg wet weight) were obtained, rinsed in cold normal saline, dried with filter paper, and weighed. The tissue was homogenized with a glass homogenizer containing 5 volumes $(\mathrm{w} / \mathrm{v})$ NEM solution ( $50 \mu$ moles $/ \mathrm{ml}$ NEM in $0.1 \mathrm{M}$ phosphate buffer, $\mathrm{pH} 7.4$, and $0.125 \mathrm{mg}$ EDTA). Norleucine was added as the internal standard. After $3 \mathrm{~min}$, the homogenate was precipitated with $20 \%$ sulfosalicylic acid $(3: 1, v / v)$ and centrifuged. The clear supernatant fluid was frozen at $-35^{\circ}$ until it was used for ion-exchange chromatography.

Similarly, groups of mice were injected with 7.5 $\mu$ moles L-cysteine in normal saline/g of body weight or $7.5 \mu$ moles each of L-cysteine and DL-homoserine/g of body weight. The animals were sacrificed at $0,0.5,1,2$, 3 , 4, and $5 \mathrm{hr}$ after injection and were processed as described above for quantitation of amino acid.

Figure 2 shows the concentration of homoserine in the plasma and the brain after injection of homoserine. Each point represents the average of two animals. From the peak value $0.5 \mathrm{hr}$ after injection, there was a rapid decrease of plasma homoserine for $2 \mathrm{hr}$ and a slow decrease from 2 to $4 \mathrm{hr}$. There was a steady increase of brain homoserine, which reached the peak at
$3 \mathrm{hr}$. From 3 to $5 \mathrm{hr}$, the concentration of homoserine in the brain was similar to that in the plasma.

Figure 3 shows the concentration of cysteine in the plasma and the brain after injection of cysteine. Each point represents the average of two animals. From a peak value $0.5 \mathrm{hr}$ after injection, there was a rapid decrease in plasma cysteine within $2 \mathrm{hr}$. There was only a minute quantity of cysteine in the plasma after $2 \mathrm{hr}$. The increase of brain cysteine was rapid; the concentration of cysteine in the brain was higher than that in the plasma from 2 to $5 \mathrm{hr}$.

Figure 4 shows the concentration of homoserine in the plasma, the liver, and the brain after injection of

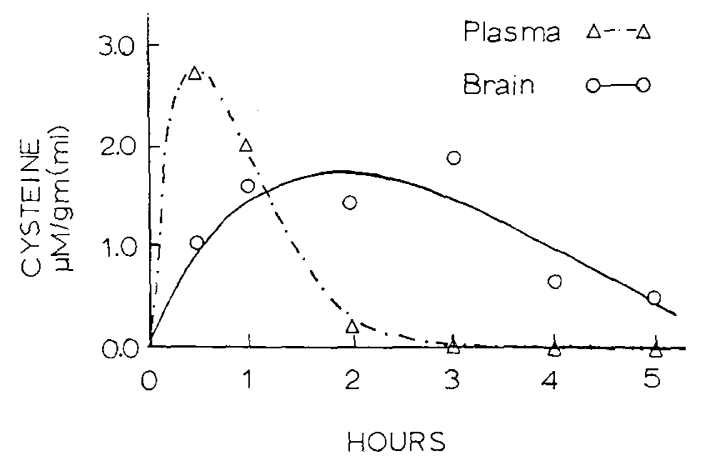

Fig. 3. Cysteine in plasma and brain of mice after intraperitoneal injection of cysteine. No measurable cysteine is detected in the plasma or brain at 0 time.

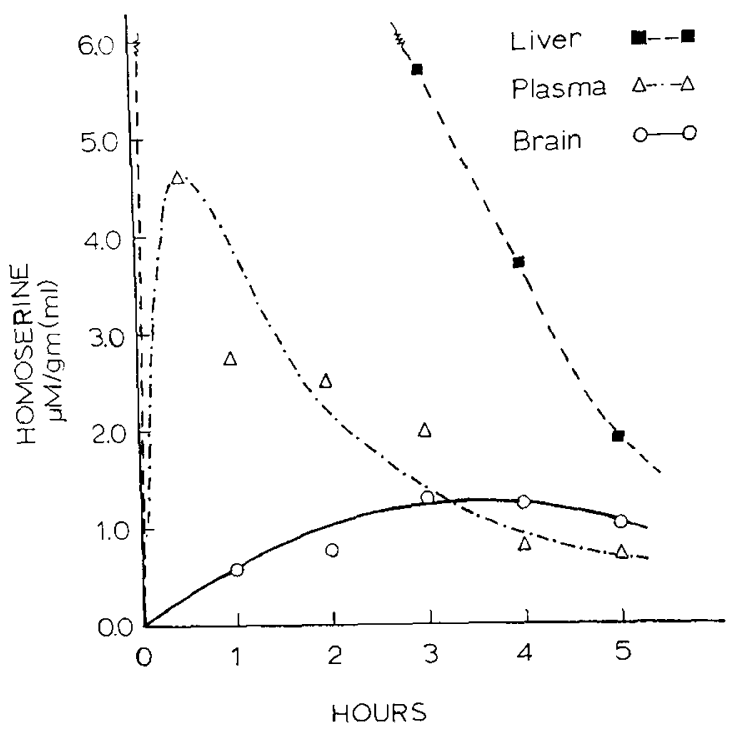

Fig. 4. Homoserine in plasma, brain, and liver of mice after intraperitoneal injection of both homoserine and cysteine. No homoserine is detected in the plasma, brain, or liver at 0 time. The concentrations of homoserine in the liver are 12.90 and $10.62 \mu$ moles $/ \mathrm{g}$ at 1 and $2 \mathrm{hr}$, respectively. 
both homoserine and cysteine. Each point represents the average of two animals. As expected, the liver contained more homoserine than either the plasma or the brain, owing to the route of administration. The concentrations of homoserine in the plasma and in the brain after injection of both amino acids were very similar to those after injection of homoserine alone.

Figure 5 shows the concentration of cysteine in the plasma, the liver, and the brain after injection of both homoserine and cysteine. Each point represents the average of two animals. The concentration of cysteine in the brain was higher than that in the plasma and in the liver from 2 to $5 \mathrm{hr}$, and was very similar to that after the injection of cysteine alone.

Figure 6 shows the concentration of cystathionine in

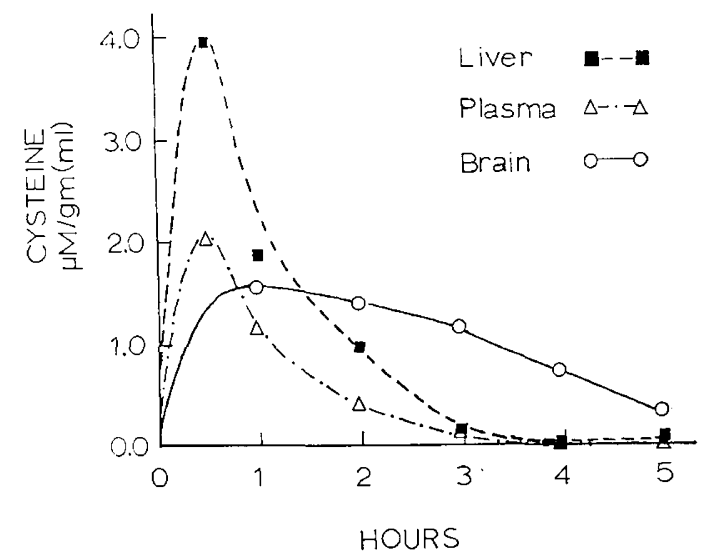

Fig. 5. Cysteine in plasma, brain, and liver of mice after intraperitoneal injection of both homoserine and cysteine. No measurable cysteine is detected in the plasma, brain, or liver at 0 time.

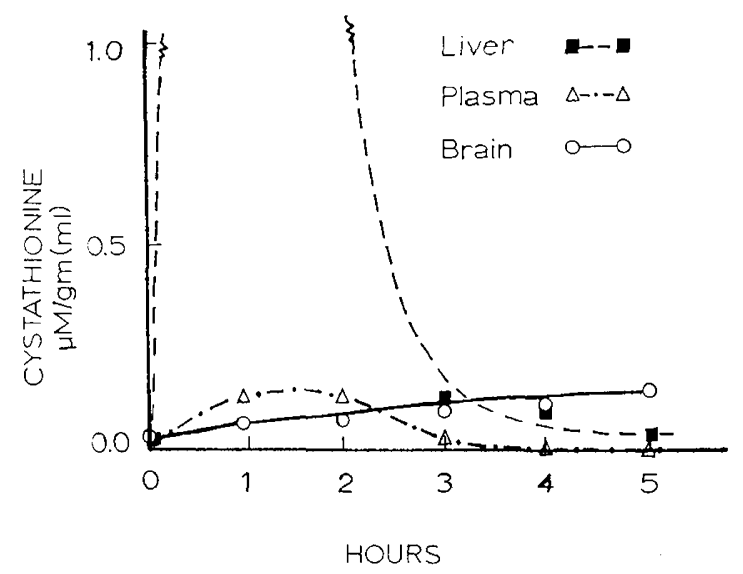

Fig. 6. Cystathionine in plasma, brain, and liver of mice after intraperitoneal injection of both homoserine and cysteine. No measurable cystathionine is detected in the plasma at 0 time. Liver cystathionine concentrations are 6.32 and $3.94 \mu$ moles/g at $\mathrm{l}$ and $2 \mathrm{hr}$, respectively.
Table I. Brain cystathionine, micromoles per gram, $5 \mathrm{hr}$ after injection

\begin{tabular}{lccc}
\hline & $\begin{array}{c}\text { No. of } \\
\text { animals }\end{array}$ & Mean $\pm \mathrm{sD}$ & $P$ \\
\hline Saline & 6 & $0.023 \pm 0.011$ & \\
Homoserine & 6 & $0.042 \pm 0.013$ & $<0.02$ \\
Cysteine & 6 & $0.069 \pm 0.017$ & $<0.01$ \\
Cysteine and homoserine & 6 & $0.143 \pm 0.022$ & $<0.01$ \\
\hline
\end{tabular}

the plasma, the liver, and the brain after injection of both homoserine and cysteine. Each point represents the average of two animals. From 2.5 to $5 \mathrm{hr}$, the concentration of cystathionine in the brain was higher than that in the plasma, suggesting that the brain was able to concentrate cystathionine from the plasma or that it had synthesized a significant amount of cystathionine in situ.

Table I shows the concentration in micromoles per gram wet weight in brain $5 \mathrm{hr}$ after intraperitoneal injection of normal saline (controls), homoserine, cysteine, or both homoserine and cysteine. Injection of homoserine or cysteine alone resulted in a significant increase of brain cystathionine; however, after the injection of both amino acids, the cystathionine in brain was more than 6 times that in the controls.

Two animals were injected with $7.5 \mu$ moles/g of body weight DL-cysteine- ${ }^{-35} \mathrm{~S}$ with specific activity of $115,000 \mathrm{dpm} / \mu$ mole. Another two animals were injected with $7.5 \mu \mathrm{moles} / \mathrm{g}$ of body weight DL-homoserine and DL-cysteine-35S. Five hours after injection, the animals were killed and processed as usual. The cystathionine obtained from the brains of all four animals was found to be radioactive. The specific activity of the cystathionine obtained from the brains of the animals with L-cysteine- ${ }^{35} \mathrm{~S}$ injection alone was 65,000 $\mathrm{dpm} / \mu$ mole; that obtained from the brains of the animals injected with both DL-homoserine and L-cysteine${ }^{35} \mathrm{~S}$ was $67,800 \mathrm{dpm} / \mu$ mole. These observations indicate that approximately $50 \%$ of the cystathionine had been derived from cysteine and, presumably, homoserine. The identity of the cystathionine was further determined by one-dimensional descending paper chromatography with two different solvent systems and radioactivity scanning as described previously [32]. In all cases, the radioactive cystathionine had the same $R_{F}$ values as did the authentic marker.

\section{Dietary Experiments}

Ten groups of weanling female mice (C57 BL/6J) were fed with the experimental diets listed in Table II. Each group consisted of 25 animals (except $A$ and $B)$, evenly divided into 5 cages. All the cages were 
checked every day in the first 3 weeks and subsequently less frequently for abnormal appearance, behavior, or death of the animals. Initially, the animals were weighed twice weekly and then weekly. The weight of food consumed per cage of animals per week was also determined. The amino acid content of Purina rat chow was determined with ion-exchange chromatography after acid or alkaline hydrolysis. The concentration of the individual amino acid per gram of chow is shown in Table III. The amount of cysteine (or cystine) or homoserine added to the experimental diets was verified by ion-exchange chromatography of the aqueous extracts of the ground pellets. The average moisture content of the diets was $4.8 \%$.

There was no significant difference in the initial mean body weight among the different groups of animals (mean: $18.55 \mathrm{~g}$ ). Each group was fed the corresponding diet ad libitum. Group $A$, on the control diet (100\% Purina rat chow), had steady weight gain. Groups $B$ and $H$, both fed on diets containing $5 \%$ added cysteine (or cystine), had initial weight loss and slower weight gain subsequently. For 2-3 weeks, both groups of animals showed "arching of the back" and their extremities appeared to be stiff on walking. Subsequently, they behaved in the same manner as did the other groups. All other groups had steady weight gain similar to that of the control group.

At the end of 24 weeks of experimental period, complete autopsies were performed on five animals in each group, and tissues were obtained from the brain, lungs, heart, liver, spleen, suprarenals, kidneys, and intestine for light microscopy and electron microscopy. Plasma and half of the brains were obtained for the determination of amino acids by ion-exchange chromatography. The concentrations of cystathionine in the plasma and in the brains of each group of animals at 24 weeks of the experimental period were similar to those found in the corresponding groups of animals at 46 weeks of the experimental period. The results of the latter are, therefore, presented (Table VI).

There were only trace amounts of cysteine or cystine in the brain in all groups. No significant cysteine was found in the plasma. The mean cystine content (micromoles per milliliter) of plasma from groups $A-J$ was $0.040,0.040,0.050,0.067,0.044,0.032,0.044,0.044$, 0.030 , and 0.050 , respectively.

The mean concentrations of homoserine (micrograms per gram) in the brains of groups $B, C, D, E, F$ and $G$ were $1.252,0.704,0.260,0.996,0.298$, and 0.304 , respectively.

No gross abnormality was found in any group at autopsy. Light microscopy of tissues from the individ-
Table II. Experimental diets

\begin{tabular}{cccc}
\hline Diet & Purina chow, $\%$ & Homoserine, \% & Cysteine, $\%$ \\
\hline$A$ & 100 & 0 & 0 \\
$B$ & 90 & 5 & 5 \\
$C$ & 96 & 2 & 2 \\
$D$ & 98 & 1 & 1 \\
$E$ & 95 & 5 & 0 \\
$F$ & 98 & 2 & 0 \\
$G$ & 99 & 1 & 0 \\
$H$ & 95 & 0 & 5 \\
$I$ & 98 & 0 & 2 \\
$J$ & 99 & 0 & 1 \\
\hline
\end{tabular}

Table III. Amino acid content of diet A

\begin{tabular}{lrr}
\hline & $\mu$ moles $/ \mathrm{g}$ & $\mathrm{mg} / \mathrm{g}$ \\
\hline Aspartic acid & 194.0 & 32.8 \\
Threonine & 75.0 & 8.9 \\
Serine & 102.1 & 10.7 \\
Glutamic acid ${ }^{1}$ & 293.2 & 43.1 \\
Proline & 140.5 & 16.1 \\
Glycine & 202.3 & 15.2 \\
Alanine & 166.8 & 14.9 \\
Valine & 122.2 & 14.3 \\
Cystine & 10.0 & 2.4 \\
Methionine & 29.2 & 4.3 \\
Isoleucine & 86.4 & 11.2 \\
Leucine & 200.0 & 26.2 \\
Tyrosine & 52.7 & 9.6 \\
Phenylalanine & 75.5 & 12.4 \\
Tryptophan & 16.4 & 3.3 \\
Lysine & 137.5 & 38.1 \\
Histidine & 47.0 & 7.3 \\
Arginine & 102.4 & 17.7 \\
& & \\
Moisture content & & $4.8 \%$ \\
Nitrogen content & & $3.8 \%$ \\
\hline
\end{tabular}

${ }_{1}^{1}$ Asparagine overlaps with glutamic acid on column chromatography.

ual organs showed no histologic abnormality. Serial sections of the brain in the region of the hypothalamus showed normal structure and normal cellular appearance.

With the exception of the liver in groups $B$ and $H$, electron microscopy of all the organs was normal. The liver of groups $B$ and $H$ showed moderate to marked decrease in cellular glycogen. There was hypertrophy of the smooth endoplasmic reticulum and moderate disorganization of the rough endoplasmic reticulum, with curling of the cisternae near the mitochondria. These changes had been observed in the liver of patients with kwashiorkor [6] and in fasting experimental animals [2].

Table IV shows the average weight of food con- 
Table $I V$. Mean food intake ${ }^{1}$ in grams per aninial per week

\begin{tabular}{c|c|c|c|c|c|c|c|c|c|c}
\hline Week & Group A & Group B & Group $C$ & Group $D$ & Group $E$ & Group $F$ & Group $G$ & Group I & Group I \\
\hline $0^{2}$ & 18.6 & 17.1 & 18.0 & 18.3 & 19.0 & 19.6 & 19.6 & 18.4 & 17.4 & Group $J$ \\
1 & 21.8 & 9.8 & 16.6 & 17.0 & 18.7 & 20.8 & 21.6 & 13.2 & 18.8 & 21.5 \\
2 & 20.2 & 12.2 & 17.7 & 18.0 & 19.2 & 20.2 & 23.9 & 14.8 & 17.8 & 22.0 \\
3 & 21.9 & 13.6 & 15.5 & 18.1 & 19.0 & 18.5 & 21.5 & 15.0 & 19.3 & 21.4 \\
4 & 24.8 & 13.8 & 17.7 & 18.5 & 19.4 & 21.0 & 22.8 & 16.0 & 19.7 & 25.4 \\
5 & 21.7 & 14.4 & 18.6 & 19.3 & 21.3 & 20.4 & 23.4 & 15.5 & 20.2 & 23.2 \\
6 & 20.1 & 15.1 & 18.6 & 19.7 & 21.6 & 21.5 & 25.5 & 15.6 & 20.4 & 28.0 \\
7 & 24.6 & 15.0 & 19.8 & 19.4 & 22.8 & 23.8 & 26.7 & 14.6 & 19.7 & 24.5 \\
8 & 24.7 & 13.4 & 20.3 & 19.6 & 25.1 & 32.3 & 40.6 & 14.5 & 20.2 & 31.61 \\
9 & 25.7 & 17.5 & 21.2 & 22.5 & 28.1 & 25.9 & 29.2 & 15.7 & 18.9 & 29.1 \\
10 & 24.0 & 15.1 & 23.9 & 21.2 & 24.8 & 26.4 & 23.7 & 13.8 & 22.8 & 27.5 \\
12 & 23.0 & 15.0 & 21.2 & 21.3 & 22.2 & 25.8 & 24.8 & 16.0 & 24.4 & 25.9 \\
14 & 22.6 & 14.8 & 23.2 & 21.8 & 22.0 & 23.6 & 27.8 & 16.8 & 22.6 & 25.6 \\
16 & 25.8 & 14.2 & 25.7 & 26.4 & 23.7 & 32.7 & 31.3 & 20.3 & 26.0 & 28.7 \\
18 & 25.2 & 17.3 & 23.7 & 26.7 & 22.4 & 25.4 & 28.4 & 17.7 & 25.3 & 25.3 \\
20 & 26.2 & 17.4 & 25.4 & 24.9 & 21.7 & 23.7 & 27.6 & 18.1 & 25.7 & 25.4 \\
22 & 27.0 & 18.0 & 26.2 & 23.1 & 21.6 & 24.2 & 25.0 & 18.5 & 25.9 & 24.9 \\
26 & 24.1 & 17.6 & 22.5 & 20.9 & 20.7 & 23.3 & 23.5 & 17.7 & 21.5 & 23.0 \\
30 & 22.4 & 17.3 & 19.2 & 19.7 & 19.4 & 21.8 & 20.8 & 17.3 & 20.9 & 21.6 \\
34 & 21.9 & 15.8 & 19.4 & 19.0 & 20.3 & 19.4 & 20.4 & 17.4 & 19.7 & 20.9 \\
38 & 21.4 & 16.9 & 19.5 & 18.1 & 18.7 & 20.8 & 19.3 & 16.9 & 19.8 & 21.2 \\
42 & 22.0 & 15.8 & 19.0 & 18.7 & 18.1 & 19.2 & 19.9 & 16.2 & 18.4 & 19.7 \\
\hline
\end{tabular}

1 Possible loss owing to spillage could not be estimated.

${ }^{2}$ All groups of animals were fed Purina rat chow (diet $A$ ) in 0 week.

Table $V$. Body weight of mice, in grams, after 34 weeks of experimental diets

\begin{tabular}{cccc}
\hline Group & No. of animals & Mean $\pm \mathrm{sD}$ & $P$ \\
\hline$A$ & 19 & $28.53 \pm 0.786$ & \\
$B$ & 18 & $22.02 \pm 0.290$ & $<0.01$ \\
$C$ & 20 & $26.00 \pm 0.460$ & $<0.01$ \\
$D$ & 20 & $26.40 \pm 0.462$ & $<0.05$ \\
$E$ & 20 & $25.50 \pm 0.504$ & $<0.01$ \\
$F$ & 19 & $27.45 \pm 0.670$ & $\mathrm{NS}^{1}$ \\
$G$ & 20 & $27.05 \pm 0.640$ & $\mathrm{NS}$ \\
$H$ & 20 & $23.10 \pm 0.388$ & $<0.01$ \\
$I$ & 20 & $25.82 \pm 0.512$ & $<0.01$ \\
$J$ & 20 & $27.00 \pm 0.636$ & $\mathrm{NS}$ \\
\hline
\end{tabular}

1NS : not significant.

sumed per animal per week. It is seen that groups $B$ and $H$ consumed much less food per animal per week. All diets containing added cysteine had a smell of hydrogen sulfide on storing, and $\operatorname{diets} B$ and $E$ had a definite acid taste. It seemed that animals fed with diets containing large amounts of cysteine consumed less food because of the unpalatability of the diets.

At the end of 34 weeks of experiments, groups $B, C$, $E, H$, and $I$ had significantly lower body weight than the control group $A$ (Table V). All the animals, however, behaved in a similar manner as the control group. The cystathionine content of brain at the end of 46 weeks of dietary experiment is shown in Table VI. Groups $B, C, D, F, H$, and $I$ had significantly more cystathionine per gram of brain tissue than did group $A$ (control). There was only a trace amount of cystathionine in the plasma of all groups of animals.

At the end of 46 weeks, light microscopy of the organs in all groups showed no pathologic changes. Serial sections of the hypothalamic nuclei in all groups did not show any histologic abnormality. Electron microscopy of the liver in groups $B$ and $H$ showed few of the changes found in the same groups at 24 weeks of experiment.

Table VI. Brain cystathionine at 46 weeks, micromoles per gram

\begin{tabular}{cccc}
\hline Group & No. of animals & Mean $\pm \mathrm{sD}$ & $P$ \\
\hline$A$ & 10 & $0.027 \pm 0.003$ & \\
$B$ & 10 & $0.148 \pm 0.016$ & $<0.01$ \\
$G$ & 10 & $0.049 \pm 0.002$ & $<0.01$ \\
$D$ & 10 & $0.044 \pm 0.002$ & $<0.01$ \\
$E$ & 10 & $0.040 \pm 0.001$ & $<0.05$ \\
$F$ & 10 & $0.043 \pm 0.003$ & $<0.01$ \\
$G$ & 10 & $0.034 \pm 0.003$ & $\mathrm{NS}^{1}$ \\
$H$ & 10 & $0.069 \pm 0.003$ & $<0.01$ \\
$I$ & 10 & $0.036 \pm 0.002$ & $<0.02$ \\
$J$ & 10 & $0.034 \pm 0.002$ & $<0.05$
\end{tabular}

1 NS : not significant. 


\section{Breeding Experiments}

Ten groups of five male and female adult mice (C57 $\mathrm{BL} / 6 \mathrm{~J}$ ) were fed the experimental diets. After 3 weeks, the corresponding groups of males and females were mated. Each group produced normal litters. However, newborns of groups $B$ and $H$ died within the first few days of life whereas litters of all other groups survived and became normal young adults.

\section{Discussion}

Various approaches have been tried in the treatment of patients with homocystinuria. Supplementation of a patient's diet with cystine for a prolonged period produced no demonstrable improvement [8]. Methyl donors, such as betaine [17], choline [26], folic acid [7], and $B_{12}[15]$ have been used in an attempt to remove homocystine by methylating homocystine to form methionine. It has not been possible to eliminate homocystine by the use of methyl donors alone. The increase in methionine secondary to the treatment may be harmful in itself [28]. The use of lysine or arginine [11] in order to increase the excretion of homocystine has not been adequately tested.

Two other approaches seem to be promising.

$A$. Based on the assumption that methionine, homocystine, and their metabolites might be the major factors in the pathogenesis of homocystinuria, treatment by methionine restriction and cystine supplement was tested in newborn infants with homocystinuria. Preliminary observations by Komrower et al. [18] and Perry et al. [25] suggested that this form of treatment might prevent many of the clinical and pathologic abnormalities. This approach did not correct the cystathionine deficiency in these patients. More extensive and more prolonged observation is required before the desirability of this treatment can be judged.

$B$. Barber and Spaeth [1] demonstrated that a large amount of pyridoxine alone was able to eliminate homocystine from the blood and urine and to maintain plasma methionine and cystine of these patients at normal levels. Similar observations have been made by other investigators [16]. However, other patients with homocystinuria did not respond to the therapy with pyridoxine [26]

Mudd et al. [22] produced evidence that pyridoxine "activated" cystathionine synthetase by $1-2 \%$ in the "pyridoxine-responsive" patients. No increase of cystathionine excretion was demonstrated during pyridoxine treatment $[15,22]$. This did not exclude the possibility that tissue cystathionine might be increased with large doses of pyridoxine. Observations on the effect of pyridoxine treatment in homocystinurics soon after birth, therefore, are most important.

Our studies demonstrated that brain tissue of mice is able to concentrate homoserine and cysteine from the plasma. When cysteine and homoserine are provided in the diet of mice, their brains contain significantly higher concentrations of cystathionine. Part of the cystathionine has been demonstrated to be derived from labeled cysteine and, presumably, homoserine. The remaining part of the cystathionine is presumed to have been derived from homocysteine and serine. It has been demonstrated that cysteine has an inhibitory effect on the degradation of cystathionine and homoserine by cystathionase [21]. Therefore, the cysteine added to the diets of these animals may have contributed to the accumulation of cystathionine and may enhance the availability of homoserine by this mechanism. As cystathionase activity is normal in the brain tissue of homocystinuric patients [19], it seems likely that brain cystathionine may be increased when homoserine and cysteine are available. It should be pointed out that endogenous formation of cysteine and homoserine is lacking in these patients. Therefore, both these amino acids must be supplied in the diet before cystathioninuria [13] and, presumably, tissue cystathionine may be increased.

On standing, diets containing cysteine had a strong smell of hydrogen sulfide and an acid taste. This is the probable cause for the poor intake of food in animals fed with diets containing large amounts of cysteine. The unpalatability of cysteine-containing diets can be avoided by giving a diet freshly prepared daily or by replacing cysteine with cystine or calcium cystinate. Experience in the treatment of a newborn infant with homocystinuria [18] and of a newborn with maple syrup urine disease [31] yielded no difficulty in the acceptability of a completely artificial diet without any flavoring. The lack of high concentration of cysteine in the liver of our animals suggests that the electron microscopic changes in the liver are not due to a "toxic effect" of cysteine but are due to poor nutrition. This hypothesis may be tested by forced feeding to provide adequate food intake in the animals.

Olney and Ho [24] demonstrated that oral loading of L-cysteine ( $3 \mathrm{~g} / \mathrm{kg}$ of body weight) in mice produced hypothalamic lesions similar to those found in mice treated with monosodium glutamate. Our animals fed with a $5 \%$ cysteine diet consumed an equivalent of 0.7 $\mathrm{g}$ cysteine $/ \mathrm{kg}$ of body weight/day. The plasma, liver, and brain of these animals did not contain any signifi- 
cant concentration of cysteine or cystine. In addition, none of our animals developed obesity nor did we find abnormal histology in the serial sections of the hypothalamus. It appears that ingestion of relatively small amounts of cysteine, even over a long period of time, would not produce damage in mice.

Various beans and plant seeds, currently under study, contain high concentrations of homoserine lactone, free homoserine, and relatively low methionine. It seems very promising that a formula can be made which is suitable for human infant consumption.

Our observations suggest that the deficiency of cystathionine in patients with homocystinuria is correctable. Supplementation of the diet for these patients with homoserine and cysteine (cystine) in conjunction with methionine restriction or pyridoxine therapy may be used. Comparison between treatment with methionine restriction and methionine restriction together with homoserine and cysteine supplement may give valuable information as to the possible harmful effect of cystathionine deficiency in patients with homocystinuria.

\section{Summary}

1. Brain tissue was demonstrated to be able to concentrate homoserine and cysteine.

2. Mice treated with homoserine and cysteine contained significantly more cystathionine in their brains.

3. Diets containing a high concentration of cysteine became unpalatable on storing.

4. Animals on prolonged feeding of homoserine and cysteine remained fertile and produced normal litters after mating.

\section{References and Notes}

1. Barber, G. W., and Spaeth, G. L.: Pyridoxine therapy in homocystinuria. Lancet, $i: 337$ (1967).

2. Bernhard, W., AND Roulller, C.: Close topographical relationship between mitochondria and ergastoplasm in a definite phase of cellular activity. J. Biophys. Biochem. Cytol. (suppl.), 2: 73 (1956).

3. BRAY, G. A.: A simple efficient liquid scintillator for count ing aqueous solution in a liquid scintillation counter. Anal Biochem., 1: 279 (1960).

4. Brenton, D. P., Cusworth, D. C., and Gauld, G. E.: Homo cystinuria: biochemical studies of tissues including a comparison with cystathioninuria. Pediatrics, 35: 50 (1965).

5. Brigham, M. P., Stein, W. H., and Moore, S.: The concentration of cysteine and cystine in human blood plasma. J. Clin. Invest., 39: 1633 (1960).

6. Camain, R., Rouiller, C., and Dupin, H.: Evolution de la stéatose hépatique dans le kwashiorkor sous l'influence du régime hyperprotidique. Ann. Anat. Pathol., 4: 220 (1959).
7. Carey, M. C., Fennelly, J. J., and Fitzgerald, O.: Subnormal serum folate levels, increased folate clearance and effect of folic acid therapy. Amer. J. Med., 45: 26 (1968).

8. Carson, N. A. J., Gusworth, D. C., Dent, C. E., Field, C. M. B., NeIll, D. W., and Westall, R. G.: Homocystinuria: a new inborn error of metabolism associated with mental deficiency. Arch. Dis. Childhood, 38: 425 (1963).

9. Chatagner, F., Trxier, M., and Portemer, C.: Biosynthesis of cystathionine from homoserine and cysteine. Fed. Eur. Biochem. Soc. Letters, 4: 231 (1969).

10. Crawhall, J. C., and Segal, S.: The intracellular cysteine/ cystine ratio in kidney cortex. Biochem. J., 99: 19c (1966).

11. Cusworth, D. C., and Gatterean, A.: Inhibition of renal tubular reabsorption of homocystine by lysine and arginine. Lancet, ii: 916 (1968).

12. Field, C. M. B., Carson, N. A. J., Cusworth, D. C., Dent, C. E., AND NeILL, D. W.: Homocystinuria: a new disorder of metabolism (Abstract). Tenth Int. Congr. Pediat., p. 274. (Lisbon, 1962).

13. Gaull, G., Wada, Y., Schneidman, K., Rassin, D., Tallan, H., and Sturman, J.: Homocystinuria: biosynthesis of cystathionine and homolanthionine. Pediat. Res., 4: 453 (1970).

14. Gerritsen, T., Vaughn, J. G., and Waisman, H. A.: The identification of homocystine in the urine. Biochem. Biophys. Res. Commun., 9: 493 (1962).

15. Hollowell, J. G., Coryell, M. E., Hall, W. K., Findley, J. K., And Thevaos, T. G.: Homocystinuria as affected by pyridoxine, folic acid and vitamin $B_{12}$. Proc. Soc. Exp. Biol. Med., 129: 327 (1968).

16. Hooft, C., Carton, D., and Sawyer, W.: Pyridoxine treatment in homocystinuria. Lancet $i$ : 1384 (1967).

17. Komrower, G. M., AND Wong, P. W. K.: Unpublished data.

18. Komrower, G. M., Lambert, A. M., Cusworth, D. G., and Westall, R. G.: Dietary treatment of homocystinuria. Arch. Dis. Childhood, 41: 666 (1966).

19. Laster, L., Spaeth, G. L., Mudd, S. H., and Finkelstein, J. D.: Homocystinuria due to cystathionine synthetase deficiency. Ann. Intern. Med., 63: 1117 (1965).

20. Leggert-Banley, J.: Techniques in Protein Chemistry, Ed. 2, p. 350. (American Elsevier, New York, 1967).

21. Matsuo, Y., and GReEnberg, D. M.: A crystalline enzyme that cleaves homoserine and cystathionine. J. Biol. Chem., 234: 516 (1959).

22. Mudd, S. H., Edwards, W. A., Loeb, P. M., Brown, M. S., AND LASTER, L.: Homocystinuria due to cystathionine synthetase deficiency: the effect of pyridoxine. J. Clin. Invest., 49: 1762 (1970).

23. Mudd, S. H., Finkelstein, J. D., Irreverre, F., and Laster, L.: Homocystinuria: an enzymatic defect. Science, 143: 1433 (1964).

24. OLNEY, J. W., AND Ho, O.: Brain damage in infant mice following oral intake of glutamate, aspartate or cysteine. Nature, 227: 609 (1970).

25. Perry, T. L., Dunn, H. G., Hansen, S., MacDougall, L., AND WARRINGTON, P. D.: Early diagnosis and treatment of homocystinuria. Pediatrics, 37: 502 (1966).

26. Perry, T. L., Hansen, S., Love, D. L., and Crawford, L. E.: Treatment of homocystinuria with a low-methionine diet, supplemental cystine, and a methyl donor. Lancet $i$ : 474 (1968). 
27. Spackman, D. H., Stein, W. H., and Moore, S.: Automatic recording apparatus for use in chromatography of amino acids. Anal. Chem., 30: 1190 (1958).

28. Stekol, J. A., AND Szaran, J.: Pathological effects of excessive methionine in the diet of growing rats. J. Nutr., 77 : 81 (1962).

29. Tallan, H. H., Moore, S., and Stein, W. H.: L-cystathionine in human brain. J. Biol. Chem., 230: 707 (1958).

30. Tristram, G. R.: Techniques in Amino Acid Analysis, p. 61. (Technicon Corporation, Tarrytown, N.Y.)

31. Wong, P. W. K.: Unpublished observation.

32. Wong, P. W. K., Schwartz, V., And Komrower, G. M.: The biosynthesis of cystathionine in patients with homocystinuria. Pediat. Res., 2: 149 (1968).

33. Obtained from the Sigma Chemical Company, St. Louis, Mo.

34. Obtained from Cyclo Chemicals, Los Angeles, Calif.

35. Obtained from the Radiochemical Centre, Amersham, England.
36. Model TSM, Technicon Corporation, Tarrytown, N.Y.

37. Jeolco U.S.A., Inc., Medford, Mass.

38. Unilux II series, Nuclear-Chicago Corporation, Des Plaines, IIl.

39. Obtained from the Abrams Company, Chicago, Ill.

40. C57 BL/6J, Jackson Laboratory, Bar Harbor, Me.

41. Obtained from the Ralston Purina Company, St. Louis, Mo.

42. General Biochemicals, Chagrin Falls, O.

43. We wish to thank Dr. C. M. Combs and Dr. S. Bongard for the identification and examination of sections of the hypothalamic nuclei, K. Curley and E. Emmans for their technical assistance, and Dr. A. Grossman for his encouragement.

44. Supported by Public Health Service Research Grant no. RO1 NS08532 NTN

45. Requests for reprints should be addressed to: Paul W. K. Wong, M.D., M.Sc., Department of Pediatrics, Mount Sinai Hospital Medical Center, Chicago, Illinois 60608 (USA).

46. Accepted for publication June 16, 1971 . 